\title{
Health Literacy Promotion: Contemporary Conceptualizations and Current Implementations in Canadian Health Librarianship ${ }^{1}$
}

\author{
Nicole Dalmer
}

\begin{abstract}
Research questions: What are the current conceptualizations of health literacy, and what strategies are Canadian health librarians in public, academic, and hospital libraries enacting to put health literacy promotion into practice? Data sources: Serving as the basis of this scoping review, library and information science, health sciences, and interdisciplinary databases were searched using key terms relating to health literacy promotion as it relates to services, programming, or resources used in a variety of library settings. A web searched allowed for the inclusion of grey literature sources. Study selection: Data sources were searched using a combination of subject headings and keywords relating to health literacy and librarians or libraries, which served as the inclusion criteria. Sources were also selected for their Canadian context or content and for health literacy promotion programs or services that took place in academic, public, or hospital library settings. Data extraction: Data sources included journal articles, government publications, library association reports, dissertations, grey literature, reviews, and newspaper articles. Data were extracted from selected Canadian data sources, identifying the type of library in which health literacy promotion-related programs were situated, the program's scope, topics covered, and the resources used or developed. Results: The established link between low health literacy and poor health outcomes allows librarians to play an active role in promoting the quality of life of their patrons. Summaries from research articles and publications from library associations provide descriptions of health literacy promotion efforts in public libraries, followed by an examination of the role librarians play in promoting health literacy skills or knowledge in academic and hospital libraries. Conclusion: Analyses of recent health literacy initiatives and programming, including educational programs, electronic or web resources, and cross-discipline committees reveal the diversity of innovative tactics implemented by librarians to promote health literacy. Health literacy awareness is a tool all librarians can incorporate into their interactions with patrons. Current barriers and sources for future inquiry surrounding health literacy promotion in libraries highlight the need for librarians to promote their skill set as a means to gain inclusion as key players in national action plans concerning health literacy promotion.
\end{abstract}

\section{Introduction}

As health information increases in volume and complexity, librarians in public, academic, and hospital settings assume a key role in promoting health literacy as a means to aid patrons to navigate health information online and in print. To understand how librarians can aid in developing and strengthening patrons' health literacy skills, an understanding of what health literacy entails is necessary.

A search for "health literacy" in a search engine or database reveals a multitude of definitions, no two identical. The Canadian Public Health Association defines health literacy as: "skills to enable access, understanding and use of information for health" [1]. The Medical Library Association, with a slightly lengthier definition, defines health literacy as, "the set of abilities needed to: recognize a health information need; identify likely information sources and use them to retrieve relevant information; assess the quality of the information and its applicability to a specific situation; and analyze, understand, and use the information to make good health decisions" [2]. And finally, to the World Health Organization, health literacy represents the "cognitive and social skills which determine the motivation and ability of individuals to gain access to, understand, and use information in ways which promote and maintain good health" [3]. There are numerous other definitions for health literacy present in the literature, both scholarly and popular, but based on these three definitions there appears to be a common thread, namely the importance of accessing, understanding, and using information. Indeed, a means

Nicole Dalmer. ${ }^{2}$ Public Services Librarian, Herbert T. Coutts Education and Physical Education Library, University of Alberta, Edmonton AB T6G 2 G5.

${ }^{1}$ This paper is peer reviewed and the runner up in the 2012 Login Canada Student Paper Prize.

${ }^{2}$ Corresponding author (e-mail: nicole.dalmer@ualberta.ca). 
by which librarians are able to promote health literacy is through access to information. These definitions also recognize that while literacy is a necessary foundation for health literacy, health literacy appears to involve more than the ability to read or understand numbers. Context matters, as does the ability to find, understand, evaluate, and communicate health-related information. Of note, none of these definitions highlight the importance of computer literacy skills. The growing field of eHealth literacy [4] may be a means of acknowledging the vast amount of healthrelated information that is available online and the increasing degree to which people are turning to the Internet to seek out information to meet their health needs [5].

Despite these competing definitions, there appears to be a consensus as to the three levels or dimensions of health literacy: functional, interactive, and critical health literacy [6]. An awareness of these levels may be of use to librarians as a means to assess patrons' abilities, interacting with them in ways that are more relevant and useful to them. As Nutbeam [6] discusses, functional health literacy includes knowing how to access health information and the ability to understand and communicate information about health. Interactive health literacy includes the ability to extract information from different forms of communication and the ability to make inferences. Critical health literacy includes the ability to analyze information and use it to advocate for personal well-being.

With definitions and conceptualizations of health literacy outlined, an exploration of the literature brings to light what Canadian librarians in public, academic, and hospital libraries are doing to put health literacy promotion into practice.

\section{Data sources}

Scoping reviews are described as "preliminary assessments of the potential size and scope of available research literature" [7]. Given the nature of scoping reviews as a means to retrieve a wide, though not exhaustive, array of articles, the author explored health sciences, library and information sciences, as well as interdisciplinary databases. The seven databases searched include: LISTA (Library, Information Science and Technology Abstracts); LISA (Library and Information Science Abstracts); OVID Medline, including in-process and other nonindexed citations; EBSCOhost CINAHL (Cumulative Index to Nursing and Allied Health Literature); EBSCOhost Academic Search Complete; Scopus; and Web of Science. To capture grey literature sources, a web search was conducted to allow for the inclusion of health literacy promotion materials that were not published through formal means such as provincial or library association reports, newsletters, or presentations. Retrieved results were published between 1990 and 2011, thus ensuring varied representations of the evolution of health promotion practices and tactics in libraries.

\section{Study selection}

Data sources were searched using a combination of subject headings and keywords of "health literacy" or "medical literacy" and variations of "librarians" or "libraries", which served as the inclusion criteria. Supporting the aim of a scoping review, search terms were intentionally broad to allow for an overarching appraisal of what scholarly or popular literature was retrievable. An example of the search strategy performed in Medline is outlined in Table 1. Results from this search were subsequently scanned and then included or excluded based on the setting in which health literacy promotion took place. Given the research questions and intended focus of this scoping review, data sources that focused on health literacy promotion in regions outside of the Canadian context were excluded as were health literacy promotion tactics that took place outside of hospital, academic, or public libraries.

\section{Data extraction}

To describe the nature and focus of health literacy promotion tactics in a variety of library settings, data were extracted from selected data sources that included journal articles, government publications, library association reports, dissertations, grey literature, reviews, and newspaper articles. To capture and describe the nature and focus of approaches to health literacy promotion in libraries, the author extracted and recorded data pertaining to the type of library in which the program was situated, the scope of the program, topics covered, and the resources used or developed. In alignment with the overarching aim of scoping reviews to capture diverse health literacy promotion efforts representative of the breadth of research retrieved, interpretations and conceptualizations of health literacy promotion strategies, titles, and abstracts were scanned and then included for their relevance and reference to health literacy promotion by librarians in Canadian public, academic, or hospital libraries.

\section{Results}

Given the established link between health literacy and health outcomes [8], the sources retrieved gave evidence of librarians' awareness of the potential they have for strengthening their patrons' health literacy skills and abilities. Studies retrieved from the literature search highlighted the barriers to health literacy that different patron groups may encounter as well as the different health literacy promotion tactics that are used in public, academic, and hospital libraries.

Health literacy is a multifaceted and potentially nebulous concept to grasp. Furthermore, from the definitions and characteristics of health literacy, there seems to be an overt connection between health consumers and health care providers. So why, as librarians, is it important to promote this complex concept? A 2008 study conducted by the Canadian Council on Learning [9] found that Canadians with lower health literacy skills are approximately two times more likely to report being in fair or poor health as those with higher skills. The prevalence of diabetes increases significantly as health literacy decreases, and a similar relationship was found for high blood pressure, arthritis, heavy drinking, injuries, stress, asthma, and frequency of hospitalization $[10,11]$. The promotion of health literacy has the capacity to enhance the quality of 
Table 1. Medline search strategy.

\begin{tabular}{|c|c|}
\hline $\begin{array}{l}\text { Search } \\
\text { no. }\end{array}$ & Search terms \\
\hline 1 & exp canada/ \\
\hline 3 & (canada or canadian $\$$ or alberta or british columbia or columbie britannique).in,jw,nw,jx. \\
\hline 4 & (saskatchewan or manitoba or ontario or quebec or new brunswick or nouveau brunswick).in,jw,nw,jx. \\
\hline 5 & $\begin{array}{l}\text { (nova scotia or nouvelle ecosse or prince edward island or ile du prince edward or newfoundland or labrador or nun?v?t or } \\
\text { nwt or northwest territories or territoires du nord ouest or yukon).in,jw,nw,jx. }\end{array}$ \\
\hline 7 & Libraries/ \\
\hline 8 & Librarians/ \\
\hline 9 & exp Libraries, Hospital/ \\
\hline 10 & Exp Libraries, Medical/ \\
\hline 11 & exp Library Services/ \\
\hline 16 & Patient Education as Topic/ \\
\hline 17 & exp Health Knowledge, Attitudes, Practice/ \\
\hline 18 & exp Consumer Health Information/ \\
\hline 19 & ((health or medical) adj2 (literacy or literate)).mp. \\
\hline 20 & (health promotion or health educat* or consumer health information or health information).mp. \\
\hline 21 & or $/ 14-20$ \\
\hline 22 & 6 and 13 and 21 \\
\hline 23 & limit 22 to $y r=" 1990-2011 "$ \\
\hline
\end{tabular}

life for many people, which may result in significant economic savings for the health care system. Canadian librarians have a sizable opportunity before them in their attempts to promote health literacy. While Canadians have higher levels of health literacy than Americans [11], the same study by the Canadian Council on Learning found that $60 \%$ of adults aged 16 and older in Canada lack the capacity to obtain, understand, and act upon health information and services and to make appropriate health decisions on their own [9].

With that in mind, as librarians interact with a wide variety of individuals, it is crucial to be cognizant of barriers to health literacy, as this can shape the resources recommended or consulted. Individuals of advanced age or lower education levels have lower health literacy rates [8]. Newcomers to Canada (especially those who speak neither English nor French), the unemployed, those of a lower socioeconomic status, and individuals living in rural communities were also found to have lower health literacy rates [10]. Research looking at determinants of health literacy is especially important for librarians aiming to promote health literacy, as this is where efforts should be concentrated. Research by the Public Health Agency of Canada's Expert Panel on Health Literacy found that daily reading habits have the single strongest effect on health literacy proficiency, with the effect amplified in older adults [12].

A study by Borman and McKenzie, both from the University of Western Ontario, found that between $6 \%$ and $20 \%$ of total reference requests in public libraries were health related [13]. Public librarians have an opportunity to enhance their communities' health literacy levels.
Compared with academic or hospital librarians, public librarians serve a more diverse clientele base that potentially includes a greater proportion of patrons who may face barriers to health literacy development. As a less formal community institution, some patrons may feel more comfortable visiting their public library to find answers to their health information needs. Public libraries can sponsor weekly or monthly educational programs to help increase the literacy levels of health care consumers in their community. These programs can focus on improving consumers' reading, numeracy, writing, speaking, or listening skills as these skills are likely to have direct impact on health literacy levels [8]. Alternatively, these education programs could focus on instructing consumers how to find and then critically evaluate online health information (for currency, accuracy, authority, etc.), and they could introduce credible sources of online health information such as MedlinePlus (which also produces tutorials for lay health users) or top-rated Canadian health websites such as those ranked by the Consumer Health Information Providers Interest Group of the Canadian Health Libraries Association [14]. Given that public libraries are often scattered through a city, these instruction sessions can be customized to address specific barriers to health literacy that exist in particular neighborhoods. Furthermore, depending on the composition of the surrounding communities, these programs can be tailored to a specific age group (for example, older adults or teens) or could be taught in a variety of languages. Findings from the selected literature also recommend that public libraries partner with local hospital or academic health libraries to have a 
medical librarian they can turn to for recommendations or specialized resources as has been recently done by Surrey Public Librarians [15]. Another common health literacy intervention strategy used by public librarians involves keeping health communication materials on hand, including instruction guides, inserts, and pamphlets created by authoritative health organizations. Patrons can easily peruse or take a handout home and are then equipped with information and links that they can investigate at home [16]. In recognition of the need for ongoing training, one initiative that Canadian library associations, networks, or interested librarians may wish to develop is a public librarians' health information librarian fellowship. While such a program has yet to be conceived, it should be given due consideration as it would allow for the enhancement of Canadian librarians as frontline health literacy referral sources by improving expertise in navigating consumer health information.

Academic health libraries serve as interesting environments for health literacy promotion, particularly given that their audience and resources vary significantly from public libraries. Academic librarians can reach students within instructional sessions by discussing the importance of health literacy and suggest different resources that these future clinicians, nurses, physical or occupational therapy students etc., can use once they are practicing as professionals. One interesting program currently in use by librarians in Nova Scotia involves academic health librarians organizing educational sessions for doctors, nurses, other health care providers, and academics in related fields [16]. In addition to facilitating discussion and development of strategies to communicate more effectively with consumers who have low literacy levels, these sessions seek feedback from the health care providers' patients to determine if and how well they have understood relevant health information, complex terms, or procedures [16]. This feedback, in turn, is used to guide further training or instruction that academic health librarians can give the health care providers. Another less-involved tactic includes the creation of "online library guides", which allows students, staff, and faculty easy access to peruse health literacy links uploaded and organized by the academic librarian. However, no such library guide was located on any of the library websites of the 10 Canadian universities with the largest student populations, representing a gap and potential area for improvement. Finally, as seen in public libraries [16], the availability of brochures, pamphlets, and other health communication materials to students, professors, and clinicians is of great value as they can then circulate these items to their patients or use them in practicum placements, clinical rotations, etc.

Health librarians working in hospital libraries are sometimes called the front line for health literacy, perhaps because they serve both the general public and health care providers. The Toronto General Hospital Patient and Family Library, equipped with a Library Patient Education Coordinator, provides patients and families with programs and computer-based patient education tools including the Oncology Interactive Education Series, a comprehensive cancer education series [17]. For those unable to physically visit the library, their website is searchable for patient guides, online brochures, and community resources [17]. In the sources consulted, health librarians in hospital libraries assume a different role in promoting health literacy. A survey conducted by a Canadian hospital librarian found that many hospital librarians are involved in internal partnerships and can therefore promote health literacy through their participation as members of hospital patient education committees and patient safety committees [16]. Librarians can use these opportunities to highlight the role that librarians can play in actively promoting health literacy skills in both health care providers and patients. Hospital librarians are also key in health information coordination as they facilitate access to both patient education materials for clinical staff and consumer health information for patients and their families [18]. Librarians can teach searching skills for locating patient education resources and best practices in finding and critically evaluating online health information. Hospital librarians were also reported as promoting patient health literacy by integrating themselves into patient care through outreach efforts [16]. This includes providing printed information in the form of consumer health packets to patients or their families. Librarians have also been identified as information conduits in hospitals, delivering information packets directly to patients' rooms in the hospital or visiting oncology floors with mobile library carts stocked with printed patient education materials and a laptop for seeking out online health information [18].

\section{Conclusion}

General trends regarding health literacy promotion in libraries or by librarians emerged from the literature. Public librarians report spending significantly more time with consumer health information requests than with other types of reference questions, indicative of librarians' needs for a better understanding of what health literacy is before they can begin to promote it [12]. Accordingly, many articles written by health librarians recognize the need for ongoing training to stay up to date with health literacy trends, newly developed resources, and related associations. Finally, one facet in which librarians in any library can promote health literacy is simply through health literacy awareness. October is health literacy month [19] and librarians can use that as a vehicle to highlight the importance and relevance of health literacy to health consumers' well-being. They can offer credible consumer health information handouts with useful resources such as the health literacy portal featured on the Canadian Public Health Association [20] website.

Despite evidence of a diversity of tools and techniques used by librarians to promote health literacy, difficulties and challenges when promoting health literacy remain. Aside from the obstacles associated with certain user groups' barriers to health literacy, librarians' inability to interpret health information or provide any sort of prescription or diagnosis to patrons limits librarians' activities to awareness campaigns, classes focusing on the critical evaluation of online health websites, and the distribution of authoritative health communication materials. 
Accordingly, librarians may have to think broadly in terms of what constitutes health literacy promotion. Given that daily reading is the best predictor of health literacy proficiency [10], summer reading programs at public libraries, which encourage daily reading habits, could be considered a promotional tactic. The other challenge lies in health literacy itself. With no consensus as to its definition, health literacy is undeniably a complex issue, particularly given that it involves the communication skills and abilities of both consumers and health care providers. Librarians must respond creatively, using a number of approaches and strategies in order to reach these different audiences.

Questions remain regarding the future of health librarians' roles in health literacy promotion. From the resources examined, the extent to which our profession should be involved in health literacy promotion has yet to be formally or conclusively determined. This is a difficult task, particularly given that readings related to health literacy promotion point towards health providers needing to assume greater responsibilities in terms of health literacy promotion, in particular, health care professionals' communication content and style when interacting with patients [21]. Health librarians will need to think creatively to interact and engage with these professionals. Finally, national action plans including the Canadian Public Health Association's Expert Panel on Health Literacy report titled "A Vision for a Health Literate Canada" [10] fail to include or feature librarians as indispensable components or prominent players in enriching Canadians' health literacy levels. Accordingly, librarians in public, academic, and hospital libraries must continually expand and promote their skill set to gain inclusion as key players in national action plans concerning health literacy promotion.

\section{References}

1. Canadian Public Health Association. Health literacy portal [Internet]. 2002 [cited 28 Nov 2011]. Available from http:// www.cpha.ca/en/portals/h-l.aspx

2. Medical Library Association. Health information literacy [Internet]. 2002 [updated 7 Oct 2011; cited 26 Nov 2011]. Available from http://www.mlanet.org/resources/healthlit/

3. World Health Organization. Health promotion glossary [Internet]. 1998 [cited 24 Nov 2011]. Available from http:// www.who.int/healthpromotion/about/HPR \%20Glossary\%201 998.pdf

4. Norman CD, Skinner, HA. eHealth literacy: Essential skills for consumer health in a networked world. $J$ Med Internet Res [Internet]. 2008 [cited 23 June 2012];8(2). Available from http://www.jmir.org/2006/2/e9/

5. Rice, RE. Influences, usage and outcomes of internet health information searching: Multivariate results from the Pew surveys. Int $J$ Med Inform [Internet]. 2006 [cited 2 Dec 2011];75,8-28. Available from: http://www.comm.ucsb.edu/ faculty/rrice/A84RiceIJMI2006.pdf

6. Nutbeam B. Health literacy as a public health goal: A challenge for contemporary health education and communication strategies into the $21^{\text {st }}$ century. Health Promot Int [Internet]. 2000 [cited 3 Dec 2011];15(3):259-67. Available from: http://heapro. oxfordjournals.org/content/15/3/259.full.pdf
7. Grant MJ, Booth A. A typology of reviews: An analysis of 14 review types of associated methodologies. Health Info Libr J. 2009;26(2):91-108. doi:10.1111/j.1471-1842.2009. 00848.x.

8. Berkman ND, Sheridan SL, Donahue KE, Halpern DJ, Crotty K. Low health literacy and health outcomes: An updated systematic review. Ann of Intern Med [Internet]. 2011 [cited 25 June 2012];155(2):97-107. Available from: www.ncbi.nlm.nih.gov/pubmed/21768583

9. Canadian Council on Learning. Health literacy in Canada: A healthy understanding [Internet]. 2008 [updated 29 Feb 2008; cited 27 Nov 2011]. Available from http://www.ccl-cca.ca/ccl/ Reports/HealthLiteracy.html

10. Murray S, Rudd R, Kirsch I, Yamamoto K, Grenier S. Health literacy in Canada: Initial results from the international adult literacy and skills survey. Ottawa: Canadian Council on Learning; 2007. 33 p.

11. Burnham E, Peterson EB. Health information literacy: A library case study. Libr Trends [Internet]. 2005 [cited 1 Dec 2011];53(3):422-33. Available from: http://www.ideals. illinois.edu/bitstream/handle/2142/1737/Burnham422433.pdf? sequence $=2$

12. Rootman I, Gordon-El-Bihbety D. A vision for a health literate Canada: Report of the expert panel on health literacy. Ottawa: Canadian Public Health Association; 2008. 48 p.

13. Borman CB, McKenzie, PJ. Trying to help without getting in their faces: Public library staff descriptions of providing consumer health information. Reference \& User Services Quarterly, 2005;45(2):140-146.

14. Consumer Health Information Providers Interest Group. Top 10 Canadian consumer health websites 2010 [Internet]. 2010 [updated 25 Nov 2011; cited 29 Nov 2011]. Available from http://www.chla-absc.ca/chipig/top-ten-2010.html

15. Thiessen T. Health literacy at Surrey Public Libraries [Internet]. 2012 [cited 26 June 2012]. Available from http:// chla-absc.ca/hlabc/node/151

16. Kars M, Baker LM, Wilson FL, editors. The Medical Library Association guide to health literacy. New York: NealSchuman Publishers; 2008.

17. Toronto General Hospital. TGH Patient and Family Library [Internet]. 2012 [cited 27 June 2012]. Available from http://www. uhn.ca/Patients_\&_visitors/health_info/PFL/TGH/index.asp

18. Shipman JP, Kurtz-Rossi S, Funk CJ. The health information literacy research project. J Med Libr Assoc. 2009;97(4):293301. doi:10.3163/1536-5050.97.4.014.

19. Osborne H. Health literacy month, October 1-31 [Internet]. 2010 [updated 16 Mar 2011; cited 2 Dec 2011]. Available from http://www.healthliteracymonth.org/hl_month_Helen_ Osborne.asp

20. Canadian Public Health Association. Health literacy portal [Internet]. 2002 [cited 2011 Nov 28]. Available from http:// www.cpha.ca/en/portals/h-l.aspx

21. Rudd RE. Low health literacy. Ann of Intern Med [Internet] 2011 [cited 25 June 2012];155(11),793-794. Available from: www.ncbi.nlm.nih.gov/pubmed/22147721 